\title{
A case of severe anorexia, excessive weight loss and high peptide YY levels after sleeve gastrectomy
}

\author{
Andrea Pucci ${ }^{1,2}$, Wui Hang Cheung ${ }^{1,2}$, Jenny Jones ${ }^{1}$, Sean Manning ${ }^{1,2,3}$, Helen Kingett ${ }^{2}$, \\ Marco Adamo², Mohamed Elkalaawy ${ }^{2,4}$, Andrew Jenkinson ${ }^{2}$, Nicholas Finer ${ }^{1,2}$, \\ Jacqueline Doyle ${ }^{2}$, Majid Hashemi ${ }^{2}$ and Rachel L Batterham ${ }^{1,2,3}$ \\ 'Department of Medicine, Rayne Institute, Centre for Obesity Research, University College London, \\ 5 University Street, London WC1E 6JJ, UK \\ ${ }^{2}$ UCLH Centre for Weight Loss, Metabolic and Endocrine Surgery, University College London Hospitals, \\ Ground Floor West Wing, 250 Euston Road, London NW1 2PG, UK \\ ${ }^{3}$ National Institute of Health Research, Biomedical Research Centre, University College London Hospitals, \\ London W1T 7DN, UK \\ ${ }^{4}$ Clinical and Experimental Surgery Department, Medical Research Institute, University of Alexandria, \\ Hadara, Alexandria 21561, Egypt
}

Correspondence should be addressed to R L Batterham Email

r.batterham@ucl.ac.uk

\section{Summary}

Sleeve gastrectomy (SG) is the second most commonly performed bariatric procedure worldwide. Altered circulating gut hormones have been suggested to contribute post-operatively to appetite suppression, decreased caloric intake and weight reduction. In the present study, we report a 22-year-old woman who underwent laparoscopic SG for obesity (BMI $46 \mathrm{~kg} / \mathrm{m}^{2}$ ). Post-operatively, she reported marked appetite reduction, which resulted in excessive weight loss (1-year post-SG: BMI $22 \mathrm{~kg} / \mathrm{m}^{2}$, weight loss $52 \%$, >99th centile of 1-year percentage of weight loss from 453 SG patients). Gastrointestinal (GI) imaging, Gl physiology/motility studies and endoscopy revealed no anatomical cause for her symptoms, and psychological assessments excluded an eating disorder. Despite nutritional supplements and anti-emetics, her weight loss continued (BMI $19 \mathrm{~kg} / \mathrm{m}^{2}$ ), and she required nasogastric feeding. A random gut hormone assessment revealed high plasma peptide YY (PYY) levels. She underwent a $3 \mathrm{~h}$ meal study following an overnight fast to assess her subjective appetite and circulating gut hormone levels. Her fasted nausea scores were high, with low hunger, and these worsened with nutrient ingestion. Compared to ten other post-SG female patients, her fasted circulating PYY and nutrient-stimulated PYY and active glucagon-like peptide 1 (GLP1) levels were markedly elevated. Octreotide treatment was associated with suppressed circulating PYY and GLP1 levels, increased appetite, increased caloric intake and weight gain (BMI $22 \mathrm{~kg} / \mathrm{m}^{2}$ after 6 months). The present case highlights the value of measuring gut hormones in patients following bariatric surgery who present with anorexia and excessive weight loss and suggests that octreotide treatment can produce symptomatic relief and weight regain in this setting. 


\section{Learning points:}

- Roux-en-Y gastric bypass and SG produce marked sustained weight reduction. However, there is a marked individual variability in this reduction, and post-operative weight loss follows a normal distribution with extremes of 'good' and 'poor' response.

- Profound anorexia and excessive weight loss post-SG may be associated with markedly elevated circulating fasted PYY and post-meal PYY and GLP1 levels.

- Octreotide treatment can produce symptomatic relief and weight regain for post-SG patients that have an extreme anorectic and weight loss response.

- The present case highlights the value of measuring circulating gut hormone levels in patients with post-operative anorexia and extreme weight loss.

\section{Background}

Bariatric surgery is the most effective treatment for severe obesity; it produces marked sustained weight loss, reduced obesity-associated co-morbidities (1) and decreased mortality (2). Roux-en-Y gastric bypass (RYGB) and sleeve gastrectomy (SG), the most common procedures that are undertaken globally (3), are known to reduce appetite and decrease caloric intake. The mechanisms that mediate these changes remain to be clarified (4). However, postoperative changes in circulating gut hormones, in particular, the anorectic hormones peptide YY (PYY) and glucagon-like peptide 1 (GLP1) and the orexigenic hormone ghrelin, have been suggested to play causal roles (5). Weight loss after RYGB and SG follows a normal distribution (6), with 'good responders' and 'poor responders' exhibiting differential appetite and gut hormone profiles (7) (8).

\section{Case presentation}

A 22-year-old woman underwent an uneventful laparoscopic SG for severe obesity (weight $135 \mathrm{~kg}$, BMI $46 \mathrm{~kg} / \mathrm{m}^{2}$ ). Her initial post-operative course was unremarkable, except she reported marked loss of appetite. One-year post-SG, she reported continued anorexia, her weight had decreased to $64.6 \mathrm{~kg}$, and her BMI had decreased to $22 \mathrm{~kg} / \mathrm{m}^{2}$; this represented a $52 \%$ body weight loss, which is at the extreme end of the normal distribution of 1-year post-operative percentage of weight loss for SG patients $(n=453)$ in our bariatric unit (Fig. 1). She did not suffer from flushing or diarrhoea. She was commenced on anti-emetics and received increased dietetic support, including advice on high-energy oral supplements.
However, her weight loss continued, and she developed continuous profound nausea with occasional vomiting.

\section{Investigation}

The patient underwent computed tomography (CT) imaging of her abdomen and pelvis, barium swallow and follow-through, oesophageal-gastro-duodenoscopy, oesophageal motility analysis and $\mathrm{pH}$ studies, all of which were normal. Psychological assessments excluded an eating disorder. Her symptoms worsened, her weight decreased to $55.8 \mathrm{~kg}$, her BMI decreased to $19.5 \mathrm{~kg} / \mathrm{m}^{2}$ and she required in-patient management with nasogastric feeding. A random gut hormone assessment revealed high circulating PYY levels $(1200 \mathrm{pg} / \mathrm{ml})$. Her fasted plasma

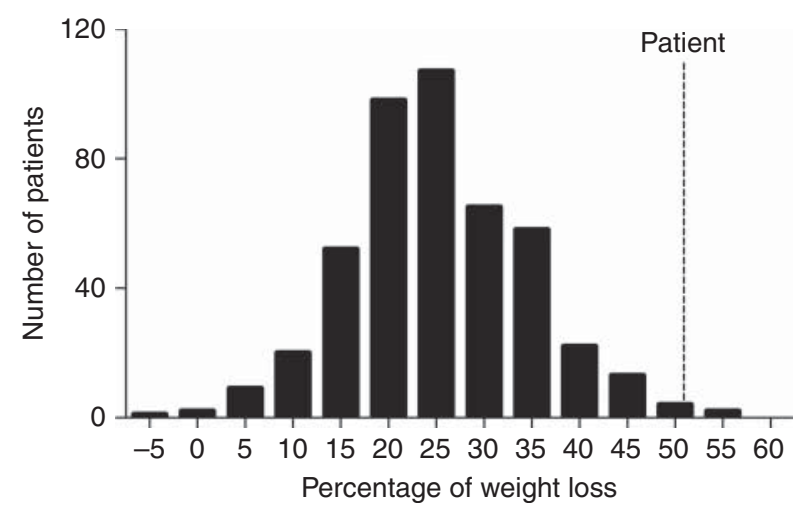

Figure 1

Histogram of the percentage of weight loss at 1-year post-surgery for all of the sleeve gastrectomies performed by our bariatric unit $(n=453)$. The vertical line at the extreme end of the normal distribution shows the percentage of weight loss of the case that represented a $52 \%$ body weight loss. 
chromogranin A and 5-hydroxy-indoleacetic acid (5HIAA) levels were normal (chromogranin A $51 \mathrm{ng} / \mathrm{ml}$ (upper limit of normal $100 \mathrm{ng} / \mathrm{ml}$ ) and 5HIAA $<4 \mathrm{ng} / \mathrm{ml}$ (upper limit of normal $13.4 \mathrm{ng} / \mathrm{ml})$ ) (9). A $3 \mathrm{~h}$ liquid meal study $(2 \mathrm{kcal} / \mathrm{ml}$, ResourcePlus Nestle, Nestle Nutrition, Croydon, UK) after an overnight $12 \mathrm{~h}$ fast was undertaken to assess her subjective appetite and circulating PYY, GLP1 and ghrelin responses. Because of nausea, she was only able to tolerate $100 \mathrm{ml}$ instead of our standard meal of $250 \mathrm{ml}$. Blood samples and appetite visual analogue scales (VASs) were taken pre-meal and then at 15, 30, 60, 90, 120, 150 and $180 \mathrm{~min}$ post-meal. In order to preserve the integrity of labile gut hormone, appropriate preservatives/inhibitors were added and blood was processed according to our published protocols (10). She was commenced on octreotide, a somatostatin analogue, $100 \mu \mathrm{g}$ subcutaneously three times a day, which resulted in an immediate appetite improvement and nausea resolution. The $100 \mathrm{ml}$ meal study was repeated after 14 days of octreotide treatment. Our patient's gut hormone results were compared to those obtained from ten female patients 3 months post-SG (control post-SG group) who underwent a $250 \mathrm{ml}$ liquid meal study. All of the patients gave written informed consent.

Plasma total PYY, active GLP1, acyl-ghrelin, total ghrelin and insulin were assayed in duplicate by commercially available ELISAs (Millipore, Watford, UK), and plasma glucose was measured by a Yellow Springs Instrument glucose analyser (Yellow Springs, OH, USA). At the start of her baseline study, despite a $12 \mathrm{~h}$ fast, she reported high nausea and low hunger. Meal ingestion increased her nausea and further suppressed her hunger (Fig. 2A and B). Her fasted circulating PYY levels were fivefold higher than those of control post-SG patients, and they increased further following nutrient ingestion (Fig. 2C). The PYY area under the curve (AUC) for her baseline meal was 5.5 -fold greater than our control postSG group's PYY AUC, despite our controls consuming twoand-a-half times more calories. Her fasted active GLP1 levels were comparable to those of the control post-SG patients (Fig. 2D). However, her peak active GLP1 was markedly elevated at 15 min post-meal (Fig. 2D). Despite her high nutrient-stimulated GLP1 levels, her nutrientstimulated plasma insulin levels were not unduly elevated (plasma insulin levels at $15 \mathrm{~min}$ post-meal: patient $31.5 \mathrm{pmol} / \mathrm{l}$; control post-SG $23 \pm 2.4 \mathrm{pmol} / \mathrm{l})$.

Both her acyl-ghrelin and total ghrelin levels were undetectable in the fasted and fed states, in contrast to the detectable levels in the control post-SG group. On octreotide treatment, her hunger increased and her nausea
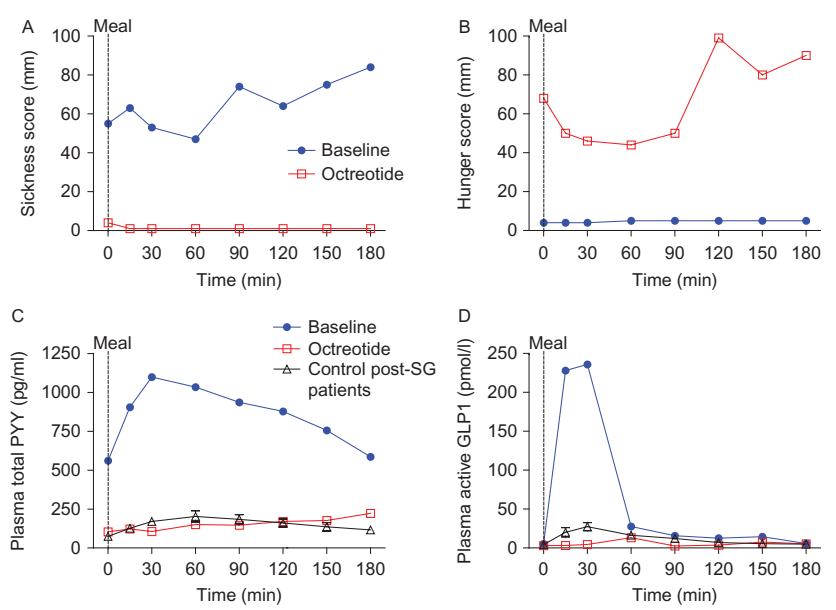

Figure 2

Graphs of the response to the test meal ( $200 \mathrm{kcal}$ for case and $500 \mathrm{kcal}$ for control post-SG group) administered at time 0 . (A) Subjective sickness score and (B) subjective hunger score (both assessed with the VAS), (C) plasma total PYY levels and (D) active GLP1 levels. Blue line and filled blue circles, case baseline meal; red line and open red squares, case treated with $100 \mu \mathrm{g}$ octreotide three times a day; black dotted line and open triangles, ten female control post-SG patients.

resolved (Fig. 2A and B). Her circulating fasted and nutrient-stimulated PYY (Fig. 2C), active GLP1 (Fig. 2D) and insulin levels were suppressed (15 min post-meal $3.2 \mathrm{pmol} / \mathrm{l})$. Her plasma acyl-ghrelin and total ghrelin levels remained undetectable.

\section{Treatment}

The patient continued with $100 \mu \mathrm{g}$ octreotide injected subcutaneously three times a day for 4 months and was then switched to long-acting octreotide, $20 \mathrm{mg}$ sandostatin LAR, administered intramuscularly every 3 weeks. During this time, her nausea and vomiting completely resolved, her appetite increased and her weight increased to $63.4 \mathrm{~kg}$.

\section{Discussion}

SG, which involves removing $90 \%$ of the gastric fundus while leaving the rest of the gastrointestinal tract intact, has recently been advocated as a 'stand-alone' bariatric procedure. However, it has become apparent, at least in the short- to medium-term, that the weight loss and metabolic benefits post-SG are comparable to RYGB (11). Consequently, the number of patients that underwent SG globally per annum increased from $\sim 25000$ in 2008 to 95000 in 2011 (3). Furthermore, research efforts have identified that mechanisms other than restriction and/or 
malabsorption underlie the sustained weight-loss effects and weight-loss-independent glycaemic improvements of these two procedures (5). Decreased energy intake, as a consequence of reduced hunger, altered food preferences and changes in food reward, is a key driver of the sustained weight loss that follows SG and RYGB. Post-operatively, nutrient-stimulated circulating levels of the anorectic gut hormones PYY and GLP1 are markedly increased, whereas plasma levels of the orexigenic hormone ghrelin are reduced post-SG and are lower than those seen after RYGB (12). These post-operative circulating gut hormone changes have been suggested to contribute to the altered feeding behaviour (5). We and others have reported that weight loss following SG and RYGB is variable and follows a normal distribution (6) (13). Interestingly, 'poor' and 'good' weight loss responders exhibit differential appetite and gut hormone changes post-surgery (7) (8).

We report the first case of a patient post-SG with profound anorexia and excessive weight loss coupled with high fasted PYY levels and elevated nutrient-stimulated GLP1 and PYY levels. Unlike in our control post-SG patients, we were unable to detect either acyl-ghrelin or total ghrelin in our patient at baseline. Previously, we have shown that exogenous PYY administration suppresses circulating ghrelin levels (14) (15), and a similar mechanism may be at work in the present case, with high endogenous PYY levels suppressing ghrelin. Our patient reported disabling nausea with occasional vomiting, symptoms that are entirely consistent with elevated PYY and GLP1 levels (16) (17). Studies that were undertaken in 'poor' as compared to 'good' weight loss responders have suggested that variability in postoperative gut hormone responses may contribute to variable weight loss outcomes (7) (8). The present case further supports this hypothesis. However, the biological mechanisms that underlie post-operative gut hormone variability remain to be elucidated. High nutrientstimulated GLP1 levels have been suggested by some but not all researchers to contribute to post-RYGB hyperinsulinaemic hypoglycaemia (18), a complication that affects $\sim 0.1 \%$ of patients post-RYGB (19). Octreotide administration produces symptomatic relief in some of these patients (20), and in others RYGB reversal has been beneficial (21). However, surgical reversal is not possible following SG. Interestingly, there have been reports of resolution of post-RYGB hyperinsulinaemic hypoglycaemia that have allowed medical therapy to be discontinued (21). Possible future outcomes for our patient are that her gut hormone profile could 'normalise', which would allow the withdrawal of octreotide therapy or that an increased understanding of enteroendocrine cell biology may enable the selective targeting of her GLP1- and PYY-producing enteroendocrine L-cells. There are some limitations to the present study. We compared the case patient's nutrientstimulated gut hormone levels to those measured in a relatively small number of control patients who were 3 months post-SG. Thus, the case patient had a lower BMI and greater weight loss as compared to the control post-SG group. These differences in weight loss and interval postSG could have impacted the circulating gut hormone levels (22). In addition, the case patient could only tolerate $100 \mathrm{ml}$ (200 kcal) of the liquid test meal as compared to the $250 \mathrm{ml}(500 \mathrm{kcal})$ consumed by the control post-SG group, which makes a direct comparison difficult. However, given that nutrient-stimulated plasma GLP1 and PYY levels are proportionate to the calorie load consumed, it is likely that the matching of the caloric loads would have further increased the difference between the case patient and the control group.

\section{Conclusion}

The present case highlights the value of measuring gut hormones in patients following SG who present with anorexia and excessive weight loss and suggests that octreotide treatment can produce symptomatic relief and weight regain for patients in this challenging clinical setting.

\section{Declaration of interest}

The authors declare that there is no conflict of interest that could be perceived as prejudicing the impartiality of the research reported.

\section{Funding}

This work was supported by the Rosetrees Trust (grant number M262-CD1).

\section{Patient consent}

Full informed consent was obtained from the patient before drafting the case report.

\section{Author contribution statement}

A Pucci, W H Cheung, S Manning, H Kingett, M Adamo, M Elkalaawy, A Jenkinson, N Finer, J Doyle, M Hashemi and R L Batterham were directly involved in the management of the patients. A Pucci, W H Cheung and $S$ Manning undertook the meal studies. J Jones and $R$ L Batterham undertook and analysed the hormone assays. A Pucci and R L Batterham drafted the case report. All of the authors contributed to and approved and the final draft of the report. 


\section{References}

1 Schauer PR, Bhatt DL, Kirwan JP, Wolski K, Brethauer SA, Navaneethan SD, Aminian A, Pothier CE, Kim ES, Nissen SE et al. 2014 Bariatric surgery versus intensive medical therapy for diabetes - 3-year outcomes. New England Journal of Medicine 370 2002-2013. (doi:10.1056/ NEJMoa1401329)

2 Sjostrom L, Narbro K, Sjostrom CD, Karason K, Larsson B, Wedel H, Lystig T, Sullivan M, Bouchard C, Carlsson B et al. 2007 Effects of bariatric surgery on mortality in Swedish obese subjects. New England Journal of Medicine 357 741-752. (doi:10.1056/NEJMoa066254)

3 Buchwald H \& Oien DM 2013 Metabolic/bariatric surgery worldwide 2011. Obesity Surgery 23 427-436. (doi:10.1007/s11695-012-0864-0)

4 Scott WR \& Batterham RL 2011 Roux-en-Y gastric bypass and laparoscopic sleeve gastrectomy: understanding weight loss and improvements in type 2 diabetes after bariatric surgery. American Journal of Physiology. Regulatory, Integrative and Comparative Physiology 301 R15-R27. (doi:10.1152/ajpregu.00038.2011)

5 Madsbad S, Dirksen C \& Holst JJ 2014 Mechanisms of changes in glucose metabolism and bodyweight after bariatric surgery. Lancet Diabetes \& Endocrinology 2 152-164. (doi:10.1016/S22138587(13)70218-3)

6 Manning S, Pucci A, Carter NC, Elkalaawy M, Querci G, Magno S, Tamberi A, Finer N, Fiennes AG, Hashemi M et al. 2014 Early postoperative weight loss predicts maximal weight loss after sleeve gastrectomy and Roux-en-Y gastric bypass. Surgical Endoscopy 29 1484-1491. (doi:10.1007/s00464-014-3829-7)

7 le Roux CW, Welbourn R, Werling M, Osborne A, Kokkinos A, Laurenius A, Lönroth H, Fändriks L, Ghatei MA, Bloom SR et al. 2007 Gut hormones as mediators of appetite and weight loss after Roux-en-Y gastric bypass. Annals of Surgery 246 780-785. (doi:10.1097/SLA. 0b013e3180caa3e3)

8 Dirksen C, Jorgensen NB, Bojsen-Moller KN, Kielgast U, Jacobsen SH, Clausen TR, Worm D, Hartmann B, Rehfeld JF, Damgaard M et al. 2013 Gut hormones, early dumping and resting energy expenditure in patients with good and poor weight loss response after Roux-en-Y gastric bypass. International Journal of Obesity 37 1452-1459. (doi:10.1038/ijo.2013.15)

9 Carling RS, Degg TJ, Allen KR, Bax ND \& Barth JH 2002 Evaluation of whole blood serotonin and plasma and urine 5-hydroxyindole acetic acid in diagnosis of carcinoid disease. Annals of Clinical Biochemistry 39 577-582. (doi:10.1177/000456320203900605)

10 Chandarana K, Drew ME, Emmanuel J, Karra E, Gelegen C, Chan P, Cron NJ \& Batterham RL 2009 Subject standardization, acclimatization, and sample processing affect gut hormone levels and appetite in humans. Gastroenterology 136 2115-2126. (doi:10.1053/j.gastro.2009.02.047)

11 Lee WJ, Pok EH, Almulaifi A, Tsou JJ, Ser KH \& Lee YC 2015 Medium-term results of laparoscopic sleeve gastrectomy: a matched comparison with gastric bypass. Obesity Surgery. In press. (doi:10.1007/ s11695-015-1582-1)

12 Yousseif A, Emmanuel J, Karra E, Millet Q, Elkalaawy M, Jenkinson AD, Hashemi M, Adamo M, Finer N, Fiennes AG et al. 2014 Differential effects of laparoscopic sleeve gastrectomy and laparoscopic gastric bypass on appetite, circulating acyl-ghrelin, peptide YY3-36 and active GLP-1 levels in non-diabetic humans. Obesity Surgery 24 241-252. (doi:10.1007/s11695-013-1066-0)

13 Hatoum IJ, Greenawalt DM, Cotsapas C, Reitman ML, Daly MJ \& Kaplan LM 2011 Heritability of the weight loss response to gastric bypass surgery. Journal of Clinical Endocrinology and Metabolism 96 E1630-E1633. (doi:10.1210/jc.2011-1130)

14 Batterham RL, Cohen MA, Ellis SM, Le Roux CW, Withers DJ, Frost GS, Ghatei MA \& Bloom SR 2003 Inhibition of food intake in obese subjects by peptide YY3-36. New England Journal of Medicine 349 941-948. (doi:10.1056/NEJMoa030204)

15 Batterham RL, ffytche DH, Rosenthal JM, Zelaya FO, Barker GJ, Withers DJ \& Williams SC 2007 PYY modulation of cortical and hypothalamic brain areas predicts feeding behaviour in humans. Nature 450 106-109. (doi:10.1038/nature06212)

16 Derosa G \& Maffioli P 2012 GLP-1 agonists exenatide and liraglutide: a review about their safety and efficacy. Current Clinical Pharmacology 7 214-228. (doi:10.2174/157488412800958686)

17 le Roux CW, Borg CM, Murphy KG, Vincent RP, Ghatei MA \& Bloom SR 2008 Supraphysiological doses of intravenous PYY3-36 cause nausea, but no additional reduction in food intake. Annals of Clinical Biochemistry 45 93-95. (doi:10.1258/acb.2007.007068)

18 McLaughlin T, Peck M, Holst J \& Deacon C 2010 Reversible hyperinsulinemic hypoglycemia after gastric bypass: a consequence of altered nutrient delivery. Journal of Clinical Endocrinology and Metabolism 95 1851-1855. (doi:10.1210/jc.2009-1628)

19 Sarwar H, Chapman WH, III, Pender JR, Ivanescu A, Drake AJ, III, Pories WJ \& Dar MS 2014 Hypoglycemia after Roux-en-Y gastric bypass: the BOLD experience. Obesity Surgery 24 1120-1124. (doi:10.1007/ s11695-014-1260-8)

20 Myint KS, Greenfield JR, Farooqi IS, Henning E, Holst JJ \& Finer N 2012 Prolonged successful therapy for hyperinsulinaemic hypoglycaemia after gastric bypass: the pathophysiological role of GLP1 and its response to a somatostatin analogue. European Journal of Endocrinology 166 951-955. (doi:10.1530/EJE-11-1065)

21 Mordes JP \& Alonso LC 2015 Evaluation, medical therapy, and course of adult persistent hyperinsulinemic hypoglycemia after Roux-en-Y gastric bypass surgery: a case series. Endocrine Practice 21 237-246. (doi:10.4158/EP14118.OR)

22 Gerner T, Johansen OE, Olufsen M, Torjesen PA \& Tveit A 2014 The post-prandial pattern of gut hormones is related to magnitude of weight-loss following gastric bypass surgery: a case-control study. Scandinavian Journal of Clinical and Laboratory Investigation 74 213-218. (doi:10.3109/00365513.2013.877594)

Received in final form 12 May 2015

Accepted 18 May 2015 